\title{
RETRACTED ARTICLE: Prediction of asphaltene precipitation by using hybrid genetic algorithm and particle swarm optimization and neural network
}

\author{
Mohammad Ali Ahmadi • Seyed Reza Shadizadeh
}

Received: 28 November 2011/ Accepted: 16 March 2012/Published online: 30 March 2012

(C) Springer-Verlag London Limited 2012

This article has been retracted at the request of the author, following concerns over the paper's integrity.

M. A. Ahmadi ( $\square)$

Department of Petroleum Engineering, Ahwaz Faculty

of Petroleum Engineering, Petroleum University of Technology,

Kut Abdollah, Ahwaz, Iran

e-mail: ahmadi6776@yahoo.com

S. R. Shadizadeh

Department of Petroleum Engineering, Abadan Faculty

of Petroleum Engineering, Petroleum University of Technology,

Abadan, Iran 